\title{
DIANTE DO TÚMULO DE JOSÉ BONIFÁCIO (*).
}

Aqui repousa o Patriarca da nacionalidade José Bonifácio de Andrada e Silva.

Sua estatura moral, sua inteligência peregrina e seu gênio político plasmaram-lhe o destino glorioso de poeta, de sábio e de estadista.

Coube-lhe o mérito e a ventura de tornar realidade o sonho frustrado do imortal Tiradentes: ver nossa pátria livre do jugo estrangeiro.

Filiado à corrente luminosa dos enciclopedistas, enxergou claro e sentiu, em tôda extensão e profundidade, o problema social e político do Brasil. E quando surgiu o momento oportuno foi-lhe possível, graças ao seu descortínio, aproveitar o ímpeto de um príncipe ambicioso, para fundar uma nação cuja estrutura, não obstante as vicissitudes, ainda permanece digna da maior admiração.

O grito do Ipiranga ecoava por todos os rincões desta terra abençoada. Mas a metrópole - como é natural - resistia tenazmente ao movimento libertador.

Tropas terrestres foram mobilizadas. A mocidade acorria, vibrante de civismo, para apoiar a luta pela efetivação da independência. João das Bottas, com suas sortidas no Recôncavo baiano, tornava já insustentável a posição dos reinóis. O velho Portugal, porém, dispunha de um elemento decisivo, em sua resistência à separação: o domínio do mar.

José Bonifácio cêdo compreendeu que, enquanto não fôsse varrida de nossas águas a esquadra portuguêsa, o Brasil não se poderia constituir em país livre e soberano.

As comunicações interiores, ainda hoje precárias, eram então pràticamente inexistentes. Só o mar permitiria a ligação com os vários centros populacionais do extenso litoral brasileiro.

(*). - Palavras proferidas pelo Contra-Almirante Norton Demaria Boiteux no Pantheon dos Andradas, em Santos, em 13 de junho de 1963. 
Urgia erradicar de Belém, São Luís, Recife, Bahia, Montevidéu e outros pontos, o obstinado e recalcitrante colonizador. E só com Marinha - robusta, aguerrida, audaciosa seria possível cumprir cabalmente tal missão.

Martim Francisco. o Ministro da Fazenda, aprovando a sugestão de Gonçalves Ledo e Pereira da Nóbrega, e apoiado firmemente por José Bonifácio, abriu, em todo o país, uma subscrição destinada a angariar os necessários recursos materiais para adquirir, armar e desenvolver uma esquadra nacional. O êxito dessa campanha foi completo.

O tesouro achava-se pràticamente exaurido. Impôs-se a dura necessidade de confiscar as propriedades portuguêsas e arrecadar suas mercadorias, porventura depositadas nas alfândegas.

Restava guarnecer os navios.

Coube a Caldeira Brant, o futuro marquês de Barbacena, nosso agente diplomático em Londres, a difícil incumbência de contratar oficiais e marinheiros inglêses para formar o núcleo da Esquadra nascente.

Foram êsses quatrocentos homens, comandados pela atrevida e legendária figura de um legítimo herói e autêntico lôbo do mar, Lord Cochrane, que vieram tripular os barcos da independência.

A ação da esquadra libertadora é por demais conhecida. Expulsou de todos os pontos de nossa costa os focos resistentes e perseguiu até a foz do Tejo os navios da frota lusa. pátria.

Consolidada a separação era preciso estruturar a nova

"A sã política é filha da moral e da razão": tal foi o princípio salutar, de sua autoria, em que o grande Andrada assentou a organização do país.

$\mathrm{O}$ arcabouço da Constituição que elaborou - sob a égide daquela imortal sentença sociológica - bem revela a superioridade e a solidez de suas convicções.

Em primeiro lugar - conforme observação do Dr. Joaquim Bagueira Leal - está nela consagrado o bem público como critério supremo da ação estatal. Nenhuma lei poderá ser estabelecida senão por utilidade pública. A lei é igual para todos, quer proteja, quer castigue. Qualquer cidadão poderá ter acesso aos cargos, sem outras credenciais que não sejam seus talentos e virtudes. Ninguém pode ser obrigado a fazer ou deixar de fazer alguma coisa, senão em virtude da lei. A liberdade religiosa é respeitada; a liberdade de opinião garan- 
tida. A propriedade está assegurada em sua plenitude, justificando-se a desapropriação sòmente por utilidade pública $e$ mediante indenização prévia.

"O Brasil - dizia êle, ao cogitar de nossas relações internacionais - quer viver em paz e amizade com tôdas as naçōes; há de tratar igualmente bem a todos os estrangeiros, mas jamais consentirá que lhe intervenham nos negócios internos do país. Se houver uma só nação que não queira sujeitar-se a esta condição, sentiremos muito, mas nem por isso nos havemos de humilhar nem submeter à sua vontade".

Dizia mais, referindo-se aos problemas internos: "O Brasil só será grande quando na face de seus filhos não houver mais distinção de raça". Fiel a êsse pensamento apresentou um projeto de abolição gradual da escravatura e outro de incorporação progressiva dos índios à civilização.

E' êsse, aliás, um dos traços predominantes de sua natureza altruística, sempre compadecida da sorte dos humildes e sofredores irmãos, índios e pretos, inocentes vítimas, então, da tirania e da exploração dos brancos. Com essa pátria, nobre, acolhedora, cavalheiresca e liberal, sonhava o velho Andrada.

Para coroar o surgimento do gigante sul-americano faltava o símbolo sagrado que sintetizasse a nova nacionalidade: faltava a Bandeira. E José Bonifácio, com base no pendão português, sem ódios nem rancores, sem quebra da necessária continuidade, mas honrando o passado e respeitando a tradição, concebeu um pavilhão nacional onde era mantida a esfera armilar de D. João VI e acrescentada a Cruz de Cristo, como recordação do seu primeiro nome e em homenagem ao Catolicismo.

Aliás - diga-se de passagem — o mesmo espírito de vinculação histórica presidiu à elaboração do atual estandarte republicano.

Tal foi a obra imperecível que nos legou

$$
\begin{aligned}
& \text { “Andrada, êsse arquiteto ousado } \\
& \text { Que amassa um povo co'a robusta mão..." }
\end{aligned}
$$

no dizer de Castro Alves.

"Se não tivemos a espada gloriosa de um Bolivar - escreve Miguel Lemos - orgulhemo-nos de haver tido a calma refletida do estadista, estimulado pelas inspirações do patriotismo e ao serviço da mais nobre das causas". 
A representação que a Marinha envia a esta solenidade patenteia o seu desêjo - infelizmente impraticável - de comparecer completa e incorporada, para testemunhar ao Patriarca o seu reconhecimento e a sua admiração.

Aqui se encontra - com o Comandante-Geral do Corpo - um luzido batalhão de Fuzileiros Navais, tropa tradicional sempre presente nos grandes lances da nossa evolução. E não poderia faltar-lhe a banda marcial para, com seus clarins e tambores, encher de vibração, neste grande dia, a alma popular.

Uma fôrça significativa da Esquadra, guarnecida por briosa marinhagem, digna herdeira de Cochrane e João das Bottas, está também surta neste pôrto. Ela vem chefiada - como uma particular reverência ao estadista que celebramos pelo próprio Almirante Comandante-em-Chefe da Esquadra.

Entre as unidades que realizam esta jornada cívica, destaca-se sem dúvida um navio. Em sua pôpa exibe orgulhosamente um nome venerável: "José Bonifácio".

Comparece ainda, na pessoa do seu Almirante Diretor, o Serviço de Documentação Geral da Marinha, órgão superior onde são zelosamente guardados, como em um relicário, todos os nomes e fatos da história naval e de sua tradição.

Finalmente, como um sinal de profundo aprêço da Armada ao seu eminente criador, aqui estão, neste Pantheon, comungando da homenagem ao Patriarca, o Secretário-Geral da Marinha, o chefe do Estado Maior da Armada e o próprio Ministro da Marinha.

E, para mais acentuar o significado desta peregrinação cultural, o Exmo. Sr. Ministro Presidente do Supremo Tribunal Federal, Dr. Antônio Carlos Lafayette de Andrada - descendente ilustre do eminente estadista - aquiesceu ao convite especial de viajar até Santos com seu filho, o Dr. Henrique Augusto Diniz de Andrada, embarcado na nau capitânea da Fôrça Tarefa que aqui aportou.

Desejou também a Administração Naval, sendo entusiàsticamente atendida, que a imprensa, representada pelo que o nosso jornalismo oferece de mais expressivo, viesse em nossa companhia, presenciar estas festividades e fazer sua cobertura. 
A presença da Marinha nesta cerimônia não é, pois, fortuita e encerra um tríplice intuito.

Resgatar, primeiro, um pouco da imensa dívida de gratidão ao seu imortal fundador, na oportunidade feliz do seu bicentenário .

Em segundo lugar trazer, a êste recinto sagrado, o testemunho de que a Marinha que êle criou é hoje uma instituição forte e pujante, sempre a serviço do Brasil.

Finalmente, a Marinha aqui se encontra, nesta hora solene, para fazer sua profissão de fé.

Patriarca venerando!

O decorrer de tua existência foi uma lição permanente de bravura moral, generosidade, honradez, visão política, liberalismo, fraternidade, fervor patriótico e dedicação ao próximo.

Esta Marinha, que te admira e reverencia, não se contenta apenas com o privilégio de ter sido um fruto precioso do teu admirável descortínio cívico. Ela deseja mais.

Ela reivindica para si, como justo legado, um quinhão do teu gênio, uma parcela da tua grandeza, uma porção do teu patriotismo.

Patriarca da Independêcia! Criador da Bandeira! Fundador da Marinha!

A Marinha que fundaste vem dizer-te, com tôda unção cívica, que a tua obra social e política não se perdeu, antes adquire cada vez mais consistência e robustez.

Ela se sente plenamente identificada com os ideais que te guiavam quando cimentaste esta Pátria gigantesca e maravilhosa.

A Marinha herdou de ti o amor ao povo, à terra e às instituições. Ela venera o passado, crê no presente e confia no porvir, radioso, que já se desenha no horizonte pátrio.

Recebe, pois, ó grande Andrada, com esta singela placa de bronze, pela tua obra imorredoura, a lídima expressão da alma marinheira.

A Posteridade indicou, para seu vulto impar, um lugar de honra no coração do Brasil. Mas o verdadeiro prêmio, que tua modéstia sempre almejou, tu mesmo definiste em dois versos imortais:

"Eu desta glória só fíco contente

Que a minha terra amei e a minha gente".

NORTON DEMARIA BOITEUX

Contra-Almirante da Armada Nacional. 